\title{
Contribution of Interferon gamma release assays testing to the diagnosis of latent tuberculosis infection in HIV-infected patients: A comparison of QuantiFERON-TB Gold In Tube, T-SPOT.TB and tuberculin skin test
}

José M Ramos ${ }^{1 *}$, Catalina Robledano¹, Mar Masiá', Sofia Belda², Sergio Padilla', Juan C Rodríguez² and Félix Gutierrez ${ }^{1,3}$

\begin{abstract}
Background: Diagnosis and treatment of latent tuberculosis infection (LTBI) is the most effective strategy to control tuberculosis (TB) among patients with HIV infection. The tuberculin skin test (TST) was the only available method to identify LTBI. The aim of the present work was to evaluate the usefulness of the interferon-gamma release assays (IGRAs): QuantiFERON-tuberculosis (TB) Gold-In-Tube test (QFG) and T-SPOT.TB for the diagnosis of LTBI in a diverse cohort of HIV-infected patients.

Methods: A prospective study was carried out in consecutive patients cared for in a single institution in Spain from January 2009 to October 2010. IGRAs and TST were performed simultaneously. TST induration $\geq 5 \mathrm{~mm}$ was considered positive.

Results: QFG, T-SPOT.TB and TST were performed in 373 subjects. Median CD4 cell count was 470/ $\mathrm{ll}$ with a median

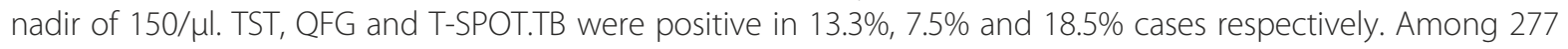
patients with neither past or current TB nor previous treatment for LTBI and who had TST results, a positive TST result was obtained in $20(7.2 \%)$ cases. When adding QFG results to TST, there were a total of $26(8.6 \%)$ diagnoses of LTBI. When the results of both IGRAs were added, the number of diagnoses increased to 54 (17.9\%) (incremental difference: 10.7\% [95\% confidence interval [CI]:5.3-16.2\%] [p < 0.001]), and when both IGRAs were added, the number of diagnoses reached 56 (18.5\%) (incremental difference: 11.3\% [95\% Cl:5.7\%-16.9\%] [p < 0.001]). Patients with a CD4 cell count greater than 500 cells/ $\mu$ and prior stay in prison were more likely to have a diagnosis of LTBI by TST and/or QFG and/or T-SPOT.TB (adjusted odds ratio [aOR]: 3.8; 95\% Cl, $1.4-9.9$; and aOR: 3.3; 95\% Cl, $1.3-8.3$, respectively).
\end{abstract}

Conclusions: IGRAs were more sensitive than TST for diagnosis of M. tuberculosis infection in HIV-infected patients. Dual sequential testing with TST and IGRAs may be the optimal approach for LTBI screening in this population.

\footnotetext{
* Correspondence: jramosrincon@yahoo.es

${ }^{1}$ Infectious Diseases Unit, Hospital General Universitario de Elche, Camino de la Almazara, 12, 03203, Elche, Alicante, Spain

Full list of author information is available at the end of the article
} 


\section{Background}

Diagnosis and treatment of latent tuberculosis infection (LTBI) is the most effective strategy to control tuberculosis (TB) among patients with HIV infection [1,2]. The tuberculin skin test (TST), the only available method to identify LTBI for more than a century, is known to have major constraints [3], including a reduced sensitivity in HIV-infected patients as compared with the general population, particularly in those with low CD4 cell counts [4].

The development of in vitro blood tests to evaluate cell-mediated immune response against Mycobacterium tuberculosis ( $M$. tuberculosis) has been a major advance for the diagnosis of LTBI. The interferon-gamma release assays (IGRAs) measure T-cell release of interferon- $\gamma$ (IFN- $\gamma$ ) following stimulation by antigens that are unique to $M$. tuberculosis including early-secreted antigenic target 6 (ESAT-6) and culture filtrate protein 10 (CFP-10), which are encoded by genes located within the region of difference 1 (RD1) segment of the $M$. tuberculosis genome [5]. These antigens are more specific for $M$. tuberculosis than those in the purified protein derivate (PPD) used in the TST because they are not shared with any BacilleCalmette-Guérin (BCG) vaccine strains. However, at least 3 species of nontuberculous mycobacteria also have the RD1 antigens as M. kansasii, M. marinum and M. szulgai. QuantiFERON-TB Gold In-Tube test (QFG) (Cellestis, Carnegie, Australia) measures the level of soluble IFN- $\gamma$ produced in whole blood by enzyme-linked immunosorbent assay (ELISA), and the T-SPOT.TB (Oxford Immunotec, Abingdon, UK) assay detects the number of IFN- $\gamma$-producing cells represented as spot-forming units (SFU). The IGRAs present practical and theoretical advantages over TST, and the US Centers for Disease Control (CDC) have released guidelines for using these assays to detect $M$. tuberculosis infection in certain circumstances [6].

Published data on the performance of the IGRAs in patients with HIV infection are limited and discordant [710]. Moreover, only a few studies have compared both IGRAs with TST in the diagnosis of LTBI among HIVinfected individuals [11-13]. To determine the real performance of these tests for the diagnosis of LTBI in HIV-infected patients, large studies that include a consecutive series of patients with a broad spectrum of HIV disease should ideally be performed. Given the reduced sensitivity of TST in those patients, evaluating the contribution of IGRAs to conventional TST is critical to decide if these tests should be incorporated into clinical practice in HIV medicine. To our knowledge, there is little information. The aim of the present work was to evaluate the usefulness of the IGRAs in a diverse cohort of HIVinfected patients. In this investigation, patients with different stages of HIV disease were studied to assess the tests, and the characteristics of patients that provided a positive IGRAs result were carefully examined.

\section{Methods}

\section{Patients and samples}

Patients were recruited into the study at the outpatient HIV clinic of a university hospital (Hospital General Universitario de Elche, Alicante, Spain). Eligible patients were all HIV-infected adults (age $\geq 15$ years) cared for in the clinic from January 2009 to October 2010. The study was approved by the Ethics Committee of Hospital General Universitario de Elche, and all the patients gave their written informed consent.

Demographical and clinical data including age, sex, nationality, HIV transmission route, years from diagnosis of HIV infection, CDC category, AIDS events, and antiretroviral treatment (ART) received prior to the study were recorded from the patients. Details were taken of previous treatment for positive TST or past or current TB, BCG vaccination status, history of household contact with TB cases, intravenous drug use, and history of previous stay prison or drug rehabilitation unit. Data were also collected about immunologic status (nadir CD4 cell count, CD4 cell count and percentage at the time of evaluation) and plasma HIV-1 RNA viral load. The past $\mathrm{TB}$ was referred by the patient or collected from clinical records. Current TB diagnosis was based on the results of clinical and radiologic examination and/or isolation of M. tuberculosis from sputum or other specimen (urine, lymph node and cerebrospinal fluid). LTBI was defined by a previous positive TST performed in our clinic or in another clinic.

\section{Procedures}

Blood samples were collected for measurement of the IGRAs tests QFG and T-SPOT.TB and a conventional TST was performed simultaneously in a blinded fashion. Study participants were injected with $0.1 \mathrm{ml}$ of tuberculin (2 tuberculin units of PPD) (Tuberculina PPD; Evans 2UT, UCB Pharma, S.A. Madrid, Spain) in accordance with the American Thoracic Society guidelines [14]. The skin induration was measured with a rule at 48-72 hours after the inoculation. The size of the induration equal or higher than $5 \mathrm{~mm}$ was considered positive. The previous BCG vaccination did not change the size limits for the tuberculin reaction. The result was considered to be invalid or not read, if the patient did no come to measure the induration and was impossible to contact him/her. All patients with a positive tuberculin test who had not been previously treated, received chemoprophylaxis with isoniazid for 6-9 months. Patients with a positive IGRA plus a positive TST also received isoniazid chemoprophylaxis. Their doctors in charge, who decided to start chemoprophylaxis or not according to additional 
accompanying factors individually managed patients with a positive IGRA, but negative TST.

For QFG, whole blood was collected from each patient and inoculated in three heparinized tubes of $1 \mathrm{ml}$ each: one containing TB antigens (ESAT-6, CFP-10, and TB7.7), a positive control tube containing phytohemagglutinin, and a null control. Blood samples were incubated for 16$20 \mathrm{~h}$ at $37^{\circ} \mathrm{C}$. Plasma samples were then harvested for IFN- $\gamma$ quantification by a single-step sandwich-type ELISA. The test was performed according to manufacturer's instructions (Cellestis, Carnegie, Australia) [15]. Optical densities were interpreted using specific software provided by the manufacturer. The result was considered to be positive if the IFN- $\gamma$ level after stimulation with TB antigens minus negative control was $\geq 0.35 \mathrm{IU} / \mathrm{ml}$ and $\geq 25 \%$ of the negative control. The test was considered negative if the IFN- $\gamma$ level was $<0.35 \mathrm{IU} / \mathrm{ml}$ (after subtraction of the negative control). The test result was considered to be indeterminate if (1) the negative control was $\geq 8.0 \mathrm{IU} / \mathrm{ml}$ or $(2)$ the positive control was $<0.5 \mathrm{IU} / \mathrm{ml}$.

The T-SPOT.TB test was performed according to the recommendations of the manufacturer (Oxford Immunotec, Abingdon, UK) [16]. We use T-Cell Xtend (Oxford Immunotec, Abingdon, UK) reagent that is added to blood samples in the laboratory immediately before running the T-SPOT.TB assay. It allows blood samples to be processed up to 32 hours after venopuncture without affecting the accuracy of the test. Concisely, peripheral blood mononuclear cells were spared by centrifugation from an $8 \mathrm{ml}$ heparinized blood sample and then placed into four wells $\left(2.5 \times 10^{5}\right.$ cells per well). The wells were stimulated with $50 \mu \mathrm{L}$ each of phytohemagglutinin (positive control), ESAT-6, CFP-10, and $\mathrm{AIM}^{\circledR} \mathrm{V}$ medium (Invitrogen. USA) (negative control). The wells were incubated for $16-20 \mathrm{~h}$ at $37^{\circ} \mathrm{C}$ in $5 \%$ $\mathrm{CO} 2$, washed, and developed with a conjugate against the antibody used and an enzyme substrate. The SFUs were counted with an USB Microscope (MicroCapture) [17], by one observer in case of doubt by two observers. The results of T-SPOT-TB were interpreted according to the following criteria:

(1) Manufacturer's criteria [16]. A result was considered to be positive if the number of SFUs was $>5$ (after subtraction of the SFUs of the negative control). If the negative control well was between 6 and 9 SFUs, the result was considered positive if the number of SFUs in the antigen well was $>2 \mathrm{x}$ SFUs negativecontrol. The test result was considered to be negative if the above criteria were not met and the positive control was valid. The result was considered to be invalid if the SFUs of the negative control was $>10$ or if the SFUs of the positive control well was $<20$ SFUs.
(2)Food and Drugs Agency (FDA) of the US criteria [18]. These interpretation criteria included a borderline interpretation. A result was considered to be positive if the number of SFUs was $\geq 8$ (after subtraction of the SFUs of negative control). The result was considered borderline if SFUs was equal to 5,6 or 7 . The result was considered negative if the number of SFUs was $\leq 4$. The result was considered to be invalid if the number of SFUs of negative control was $>10$ or if $<20$ SFUs in the positive control well.

\section{Statistical analysis}

Data were analyzed using the SPSS software package version 12.0 (SPSS Inc., Chicago, Illinois, USA). Concordance between dichotomized TST, QFG and T-SPOT.TB was assessed by kappa (к) coefficient. Strength of agreement was considered 'poor' for $\mathrm{K} \leq 0.20$, 'fair' for $0.20<\mathrm{K} \leq$ 0.40 , 'moderate' for $0.40<\mathrm{K} \leq 0.60$, 'substantial' for $0.60<\kappa \leq 0.80$, and 'optimal' for $0.80<\kappa \leq 1.00$ [19]. For the analysis of agreement indeterminate and invalid tests results were excluded.

Fisher's exact test, Chi-square for lineal association, Mc Nemar's test, and Kruskal-Wallis test were used for comparisons where appropriate. Significant univariate predictors $(\mathrm{P}<0.05)$ were included in a logistic regression model to identify independent predictors measured by odds ratio (adjusted odds ratio, [aOR]) with the 95\% confidence interval $(\mathrm{CI})$. We calculate the lower and upper limits of the $95 \%$ CI for a proportion and the $\mathrm{z}$ ratio for the significance of the difference between two proportions.

\section{Results}

\section{Study population}

The three tests, QFG, T-SPOT.TB and TST, were performed in 373 subjects: Demographic and clinical characteristics of these patients are summarized in Table 1. The majority of patients were Spanish (92.5\%); 187 (50.1\%) had history of intravenous drug use, and 144 (38.6\%) had a prior AIDS-defining event. Most of them (74.5\%) were on ART.

The median HIV-1 RNA viral load was $<50$ copies/ml (range, $<50-1 \times 10^{6}$ ); 218 (58.4\%) patients had HIV-1 RNA viral load $<50$ copies $/ \mathrm{ml}$. The median CD4 cell count was 470 cells/ $\mu$ l (range, 10-1760/ $\mu \mathrm{l}) ; 62(16.6 \%)$ individuals had CD4 cell count $<200$ cells $/ \mu$ l. There were 71 patients with either: a history of previously active TB ( $\mathrm{n}=50)$, a history of previous treatment for LTBI $(\mathrm{n}=15)$, and current active TB $(\mathrm{n}=6)$. Table 1 shows the differences between those patients without and with past $(n=50)$ TB or current TB $(n=6)$ or previous positive TST treated $(\mathrm{n}=15)$. 
Table 1 Baseline demographic and clinic characteristics of 373 HIV-infected patients undergoing tuberculin skin test, QuantiFERON-TB Gold and T-SPOT-TB testing, stratified according to past or current tuberculosis (TB) and previous positive tuberculin skin test (TST)

$$
\begin{aligned}
& \text { All patients } \\
& (\mathrm{n}=373)
\end{aligned}
$$

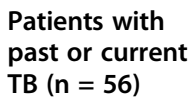

Patients with
positive TST
treated $(n=15)$

treated $(n=15)$

\section{Patients with no \\ past or current \\ TB nor positive}

\begin{tabular}{|c|c|c|c|c|c|}
\hline \multicolumn{6}{|l|}{ Demography } \\
\hline Median age, years (range) & $44(15-85)$ & $45(21-74)$ & $42(27-50)$ & $44(15-85)$ & NS \\
\hline Sex, male & $287(76.9)$ & $44(78.6)$ & $14(93.3)$ & $229(75.8)$ & NS \\
\hline $\begin{array}{l}\text { Origin from a country with } \\
\text { high prevalence of TB }\end{array}$ & $28(7.5)$ & $7(12.5)$ & $1(6.7)$ & $20(6.7)$ & NS \\
\hline \multicolumn{6}{|l|}{ HIV-related factors } \\
\hline Prior AIDS defining illness & $144(38.6)$ & $50(89.3)$ & $4(26.7)$ & $92(30.5)$ & $<0.001$ \\
\hline \multirow{2}{*}{$\begin{array}{l}\text { Median CD4 cell count, } \\
\text { cells/ } \mu \text { (range) }\end{array}$} & \multirow[t]{2}{*}{$470(10-1760)$} & 350 & \multirow[t]{2}{*}{$442(120-1200)$} & \multirow[t]{2}{*}{$500(10-1760)$} & \multirow[t]{2}{*}{0.02} \\
\hline & & $(10-1550)$ & & & \\
\hline CD4 cell count $<200 / \mu l$ & $62(16.6)$ & $20(35.7)$ & $3(20)$ & 39 (12.9) & $<0.001$ \\
\hline CD4 cell count $<350 / \mu l$ & $135(36.2)$ & $28(50)$ & $9(60)$ & $101(33.4)$ & 0.03 \\
\hline CD4 cell count $<500 / \mu l$ & $198(53.1)$ & $35(62.5)$ & $10(66.7)$ & $153(50.7)$ & 0.07 \\
\hline 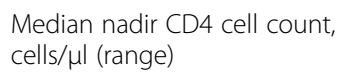 & $150(5-1650)$ & $70(5-1220)$ & $240(42-500)$ & $180(5-1650)$ & $<0.001$ \\
\hline $\begin{array}{l}\text { Median HIV-1 ARN viral load, } \\
\text { copies/ml (range) }\end{array}$ & $<50\left(0-1 \times 10^{6}\right)$ & $115\left(0-1 \times 10^{6}\right)$ & $<50(0-85486)$ & $<50\left(0-1 \times 10^{6}\right)$ & NS \\
\hline $\begin{array}{l}\text { HIV-1 RNA viral load } \\
<50 \text { copies } / \mathrm{ml}\end{array}$ & $218(58.4)$ & $35(49.3)$ & $11(74)$ & $183(60.6)$ & NS \\
\hline ART-naïve & $95(25.5)$ & $24(42.8)$ & $13(86.7)$ & $77(25.5)$ & NS \\
\hline $\begin{array}{l}\text { Median time (years) since } \\
1^{\text {st }} \text { HIV-positive test (range) }\end{array}$ & $10(0-27)$ & $12(0.1-22)$ & $12(3-24)$ & $10(0.1-27)$ & 0.001 \\
\hline BCG vaccine & $58(15.8)$ & $13(23.2)$ & $5(33.3)$ & $40(13.9)$ & 0.02 \\
\hline \multicolumn{6}{|l|}{ Risk factors for TB infection } \\
\hline Contact with patients with TB & $144(38.7)$ & $40(71.4)$ & $11(17.3)$ & $93(30.9)$ & $<0.001$ \\
\hline History of injection drug use & $187(50.1)$ & $35(62.5)$ & $14(93.3)$ & $138(45.7)$ & 0.001 \\
\hline History of prior prison stay & $102(27.3)$ & $29(51.8)$ & $13(86.7)$ & $60(19.9)$ & $<0.001$ \\
\hline Lived in a shelter or homeless & $97(26.0)$ & $22(39.2)$ & $6(40)$ & $66(21.9)$ & $<0.001$ \\
\hline Diabetes mellitus & $16(4.3)$ & $1(1.1)$ & $1(6.7)$ & $14(4.6)$ & NS \\
\hline \multicolumn{6}{|l|}{ Others } \\
\hline Hepatitis C virus co-infection & $167(45.1)$ & $33(58.9)$ & $14(93.3)$ & $120(40.0)$ & $<0.001$ \\
\hline
\end{tabular}

TST $(\mathbf{n}=302)$

\section{Diagnostic tests}

A TST result was not available in 28 (7.5\%) of 373 patients, the reason being in all the cases that the patient did not come to measure the induration, and it was impossible to contact him/her. In $13.3 \%(46 / 345)$ patients the TST was positive (induration of at least $5 \mathrm{~mm}$ ). QFG was positive in $7.5 \%(28 / 373)$ patients. T-SPOT.TB was positive in $18.5 \%(69 / 373)$ patients according to manufacturer's criteria. When T-SPOT.TB results were categorized according to FDA's criteria, 13.4\% (50/373) patients gave a positive result, and $7.2 \%(27 / 373)$ a borderline result. In the Figure 1 shows a Venn diagram where the various tests coincide in terms of positives as defined by the manufacturers. QFG and T-SPOT. TB were more often positive in patients with past or current TB or previous treatment for positive TST and in patients with contact with TB patients as summarized in Table 2.

TST, QFG and T-SPOT.TB were positive in $13.3 \%$, $7.5 \%$ and $18.5 \%$ cases; respectively. The number of indeterminate or invalid results was lower for QFG than for T-SPOT.TB (2.7\% versus $7.2 \%$; $=0.002)$. An indeterminate QFG result was statistically associated with CD4 cell count $<200 / \mu \mathrm{l}(8.1 \%$ versus $1.6 \%$; $\mathrm{p}<0.001)$. No 


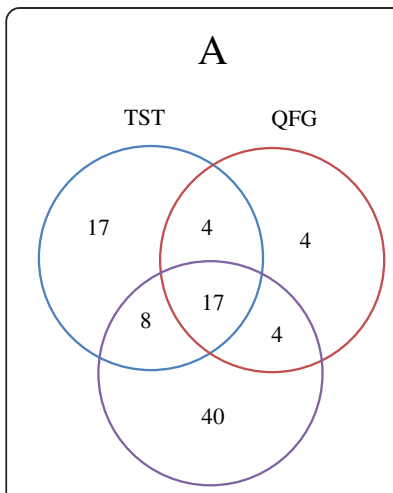

T.SPOT.TB
B

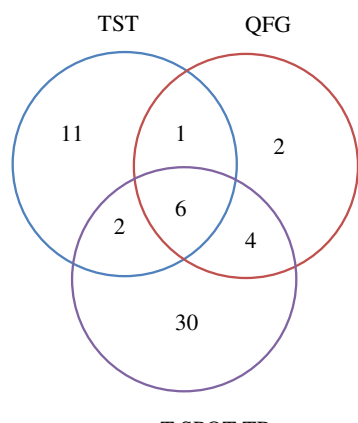

T.SPOT.TB
Figure 1 Venn diagram illustrating how often the tuberculin skin test (TST), QuantiFERON-TB Gold (QFG), and T-SPOT.TB tests coincide in terms of positives as defined by the manufacturers in 372 HIV-infected patients (A) and in 302 HIV-infected patients with no past or current TB nor treated for of latent tuberculosis infection (B). association of low CD4 cell count with indeterminate T-SPOT.TB results was found.

Table 3 illustrates the concordance between TST, QFG and T-SPOT.TB results stratified according to medical history of past or current TB or previous treatment for positive TST. Overall, agreement between TST and the IGRAs was moderate or poor. It was higher in patients with past or current TB or previous treatment for LTBI, in whom the tests were more likely to be positive. Of note, there was poor concordance between the two IGRAs $(\kappa=0.351)$, particularly when using the manufacturer's interpretation criteria for T-SPOT.TB.

\section{Contribution of IGRAs to the diagnosis of LTBI}

To assess the contribution of IGRAs to the diagnosis of LTBI, only 302 patients with no past or current TB nor previous treatment for positive TST were analyzed. A TST result was not available in $25(8.3 \%)$ and a positive result

Table 2 Comparison of tuberculin skin test (TST), QuantiFERON-TB Gold (QFG), and T-SPOT.TB in all the patients, in patients with past or current tuberculosis (TB) or previous positive tuberculin skin test (TST) and in patients with no past or current TB nor treatment for LTBI with and without TB contact

\begin{tabular}{|c|c|c|c|c|c|}
\hline \multirow[t]{2}{*}{ Test } & \multirow[t]{2}{*}{ Patients } & \multicolumn{4}{|c|}{ Results of Test } \\
\hline & & Positive & Borderline & Negative & $\begin{array}{l}\text { Indeterminate or } \\
\text { invalid }\end{array}$ \\
\hline \multirow[t]{4}{*}{ TST } & All patients $(n=373)$ & $46(12.3)$ & - & $299(80.2)$ & $28(7.5)$ \\
\hline & Patients with past or current TB or positive TST $(n=71)$ & $26(36.6)$ & - & $42(59.2)$ & $3(4.2)$ \\
\hline & $\begin{array}{l}\text { Patients with no past or current TB nor positive TST } \\
\text { without TB contact }(n=209)\end{array}$ & $7(3.3)$ & & $188(90.0)$ & $14(6.7)$ \\
\hline & $\begin{array}{l}\text { Patients with no past or current TB nor positive TST } \\
\text { with TB contact }(n=93)\end{array}$ & $13(14.0)$ & - & $69(74.2)$ & $11(11.8)$ \\
\hline \multirow[t]{4}{*}{ QFG } & All patients $(n=373)$ & $28(7.5)$ & - & $335(89.8)$ & $10(2.7)$ \\
\hline & Patients with past or current TB or positive TST $(n=71)$ & $15(21.1)$ & - & $56(78.9)$ & $0(0)$ \\
\hline & $\begin{array}{l}\text { Patients with no past or current TB nor positive TST } \\
\text { without TB contact }(n=209)\end{array}$ & $6(2.9)$ & & $198(94.7)$ & $5(2.4)$ \\
\hline & $\begin{array}{l}\text { Patients with no past or current TB nor positive TST } \\
\text { with TB contact }(n=93)\end{array}$ & $7(7.5)$ & - & $81(87.1)$ & $5(2.4)$ \\
\hline \multirow[t]{4}{*}{ T-SPOT.TB (MC) } & All patients $(n=373)$ & $69(18.5)$ & - & $278(74.5)$ & $26(7.0)$ \\
\hline & Patients with past or current TB or positive TST $(n=71)$ & $27(38.0)$ & - & $40(56.3)$ & $4(5.6)$ \\
\hline & $\begin{array}{l}\text { Patients with no past or current TB nor positive TST } \\
\text { with TB contact }(n=209)\end{array}$ & $28(13.4)$ & & $166(74.4)$ & $15(7.2)$ \\
\hline & $\begin{array}{l}\text { Patients with no past or current TB nor positive TST } \\
\text { with TB contact }(n=93)\end{array}$ & $14(15.1)$ & - & $72(77.4)$ & $7(7.5)$ \\
\hline \multirow[t]{4}{*}{ T-SPOT.TB (FDAC) } & All patients $(n=373)$ & $50(13.4)$ & $27(7.2)$ & $270(72.4)$ & $26(7.0)$ \\
\hline & Patients with past or current TB or positive TST $(n=71)$ & $22(31.0)$ & $7(9.9)$ & $38(53.5)$ & $4(5.6)$ \\
\hline & $\begin{array}{l}\text { Patients with no past or current TB nor positive } \\
\text { TST without TB contact }(n=209)\end{array}$ & $20(9.6)$ & $12(5.7)$ & $162(77.5)$ & $15(7.2)$ \\
\hline & $\begin{array}{l}\text { Patients with no past or current TB nor positive TST } \\
\text { with TB contact }(\mathrm{n}=93)\end{array}$ & $8(8.6)$ & $8(8.6)$ & $70(72.9)$ & $7(7.5)$ \\
\hline
\end{tabular}


Table 3 Concordance between tuberculin skin test (TST), QuantiFERON-TB Gold (QFG) and T-SPOT.TB in all the patients, in patients with past or current tuberculosis (TB) or previous treatment for latent TB infection (LTBI), and patients with no past or current TB nor treatment for LTBI

\begin{tabular}{|c|c|c|c|}
\hline & All patients & $\begin{array}{l}\text { Patients with past or current } \\
\text { TB or treatment for LTBI }\end{array}$ & $\begin{array}{l}\text { Patients with no past or current } \\
\text { TB nor treatment for LTBI }\end{array}$ \\
\hline \multirow[t]{2}{*}{ QFG *vs TST* } & 0.548 & 0.524 & 0.437 \\
\hline & $(0.417-0.621)$ & $(0.359-0.615)$ & $(0.233-0.663)$ \\
\hline \multirow[t]{2}{*}{ T.SPOT.TB $(M C)^{*}$ VS TST* } & 0.397 & 0.415 & 0.238 \\
\hline & $(0.268-0.515)$ & $(0.233-0.663)$ & $(0.092-0.392)$ \\
\hline \multirow[t]{2}{*}{ T.SPOT.TB (FDAC) $)^{* *}$ vs TST* } & 0.483 & 0.493 & 0.359 \\
\hline & $(0.339-0.609)$ & $(0.249-0.685)$ & $(0.176-0.541)$ \\
\hline \multirow[t]{2}{*}{ T.SPOT.TB $\left(\right.$ FDAC) ${ }^{* * *}$ vs TST* } & 0.392 & 0.482 & 0.237 \\
\hline & $(0.269-0.500)$ & $(0.243-0.665)$ & $(0.100-0.372)$ \\
\hline \multirow[t]{2}{*}{ T.SPOT.TB (FDAC)**** vs TST* } & 0.455 & 0.430 & 0.350 \\
\hline & $(0.315-0.583)$ & $(0.186-0.622)$ & $(0.171-0.533)$ \\
\hline \multirow[t]{2}{*}{ T.SPOT.TB (Mc)* vs QFG* } & 0.365 & 0.331 & 0.324 \\
\hline & $(0.255-0.437)$ & $(0.110-0.483)$ & $(0.196-0.381)$ \\
\hline \multirow[t]{2}{*}{ T.SPOT.TB $(F D A C)^{* *}$ vs QFG* } & 0.478 & 0.456 & 0.426 \\
\hline & $(0.348-0.554)$ & $(0.213-0.601)$ & $(0.259-0.504)$ \\
\hline \multirow[t]{2}{*}{ T.SPOT.TB (FDAC) ${ }^{* * *}$ vs QFG* } & 0.351 & 0.355 & 0.289 \\
\hline & $(0.250-0.411)$ & $(0.143-0.477)$ & $(0.171-0.341)$ \\
\hline \multirow[t]{2}{*}{ T.SPOT.TB $(F D A C)^{* * * *}$ vs QFG* } & 0.464 & 0.447 & 0.414 \\
\hline & $(0.336-0.560)$ & $(0.208-0.611)$ & $(0.245-0.515)$ \\
\hline
\end{tabular}

NOTE. Data are kappa (к) coefficient and lower and upper limits of the $95 \%$ confidence interval.

Mc: Manufacturer's interpretation criteria; FDAc: Food and Drug Agency's interpretation criteria.

*Excluding indeterminate results; ${ }^{* *}$ excluding invalid and borderline results; ${ }^{* * *}$ excluding invalid results and borderline results considered as positive; ${ }^{* * *}$ excluding invalid results and borderline results considered as negative.

was obtained in $7.2 \%$ (20/277). In the Figure 2 shows how often the various tests coincide in terms of positives in these 302 patients. When, we added QFG results to TST, there were a total of $26(8.6 \%)$ diagnoses of LTBI (incremental difference: $1.4 \%$ [95\% CI: $-3.1 \%-+5.7 \%]$ [p $=0.5]$ ). When adding T.SPOT.TB results interpreted according to manufacturer's criteria, the number of cases of LTBI increased to 54 (17.9\%) (incremental difference: 10.7\% [95\% CI: 5.3\%-16.2\%] [p < 0.001]), and when both QFG and T-SPOT.TB interpreted according to manufacturer's criteria were added, the number of diagnosis of LTBI reached 56 (18.5\%) (incremental difference: 11.3\% [95\% CI: $5.7 \%-16.9 \%]$ [p $<0.001])$. When the more restricted T-SPOT.TB FDA's interpretation criteria were used, the number of diagnosis of LTBI was 40 (13.2\%) (incremental difference: $6.0 \%$ [95\% CI: $0.8 \%-8.2 \%]$ [p = 0.02]), and after considering both QFG and T-SPOT.TB interpreted according to FDA's criteria, it was 42 (14.6\%) (incremental difference: $6.7 \%$ [95\% CI: $1.4 \%-11.9 \%][\mathrm{p}=0.009])$.

Factors associated with LBTI diagnosis by TST, QFG or TSPOT.TB

Table 4 shows the significantly factors associated with LBTI diagnosed by TST and/or IGRAs. Compared with patients with a TST negative, a LBTI diagnosis by a TST positive $(n=20)$ was more common in those with a higher median current CD4 (630 [range, 90-1650] versus 480 [10-1760]) $(\mathrm{p}=0.02)$, a longer time from the first HIVpositive test (11.5 [range, 0.1-27] versus 10 [range, 0-25]) $(\mathrm{p}=0.04)$, and in those with history of contact with patients with TB (65\% versus $28.5 \%)(\mathrm{p}=0.002)$, history of injection drug use $(75 \%$ versus $43.6 \%)(\mathrm{p}=0.02)$, prior prison stay $(60 \%$ versus $17 \%)(\mathrm{p}<0.001)$, those living in a shelter or being homeless (55\% versus 19.5\%) $(\mathrm{p}<0.001)$, and with hepatitis $\mathrm{C}$ virus co-infection (70\% versus $37.9 \%)(p=0.009)$. In logistic regression analysis, $a$ history of contact with patients with $\mathrm{TB}$ (aOR 4.6; CI 95\%: 1.18-18.5) and prior prison stay (aOR 4.4; CI 95\%: 1.18 - 18.7) were independently associated with a positive TST.

A statistically significant association was found between a LTBI diagnosis by either TST or QFG or T. SPOT.TB and a higher median current CD4 (580 [range, 10-1730] versus 450 [range, 10-1760] $(\mathrm{p}=0.02)$, a CD4 cell count greater than $500 \mathrm{cell} / \mu \mathrm{l}(67.9 \%$ versus 45.1\%) ( $\mathrm{p}=0.002)$, longer time from the first HIVpositive test (12 [range, 0.1-27] versus 9.5 [range, 0.1-23] years $)(\mathrm{p}=0.04)$, history of contact with patients with 


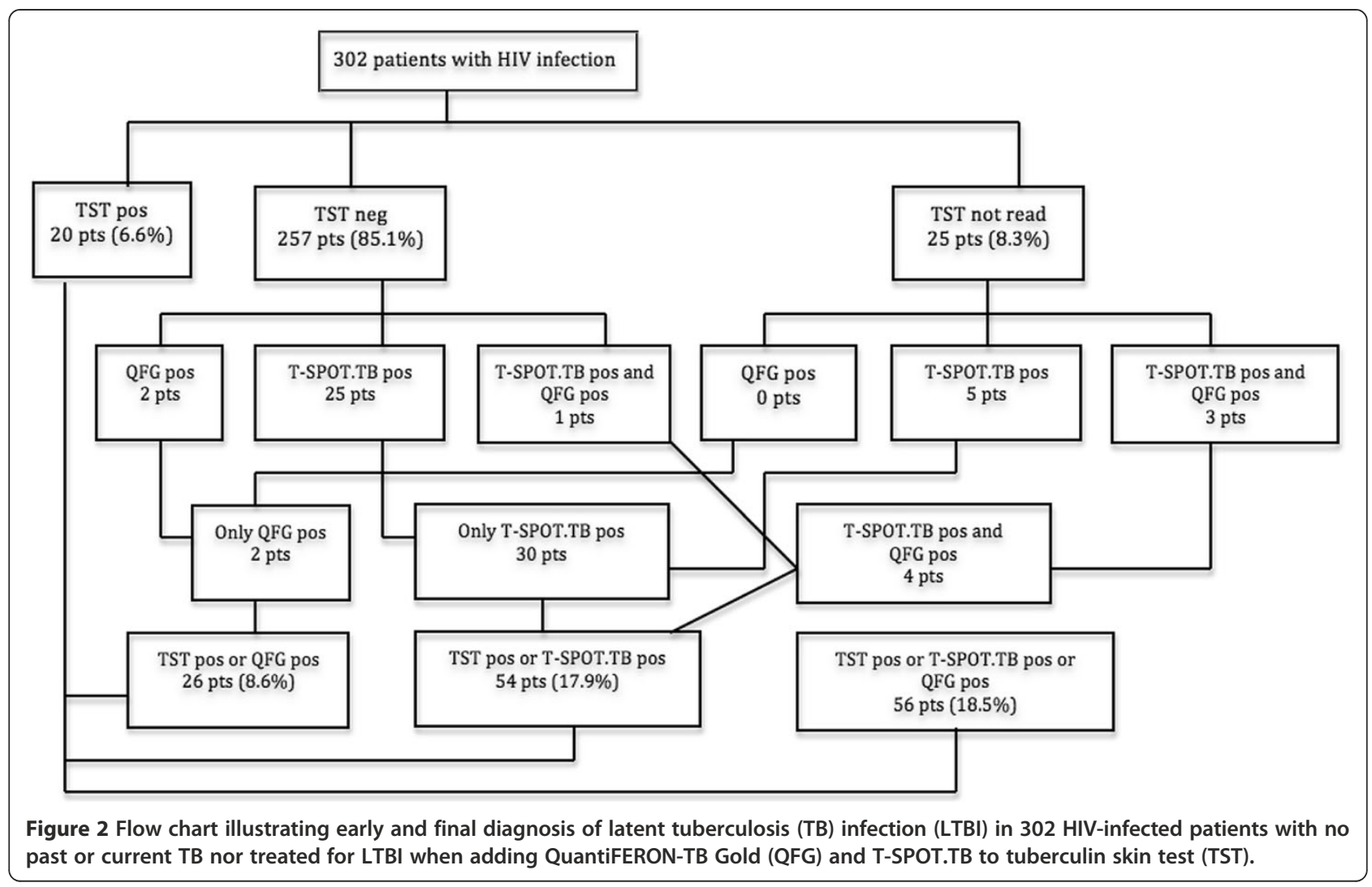

TB $(42.9 \%$ versus $28.2 \%)(\mathrm{p}=0.04)$, history of injection drug use $(58.8 \%$ versus $42.7 \%)(\mathrm{p}=0.04)$ and prior prison stay $(37.1 \%$ versus $17.9 \%)(p=0.002)$. In logistic regression analysis, patients with a CD4 cell count greater than 500 cells/ $\mu \mathrm{l}$ and prior stay in prison were more likely to have a diagnosis of LTBI (aOR 3.8; CI 95\%: 1.4 - 9.9, and aOR 3.3; CI 95\%: 1.3 - 8.3, respectively).

Table 4 Significant variables associated with latent tuberculosis infection (LTBI) stratified by tuberculin skin test (TST) or interferon-gamma release assays in 302 HIV-infected patients with no past or current tuberculosis (TB) nor LTBI

\begin{tabular}{|c|c|c|c|c|}
\hline Median CD4 cell/ul count (range) & $630(90-1650) \dagger$ & $580(10-1740)$ & $580(10-1730) \dagger$ & $450(10-1760)$ \\
\hline CD4 cell count $<350 / \mu l$ & $4(20)$ & $9(20) \zeta$ & $13(23.2)$ & $88(35.8)$ \\
\hline CD4 cell count $<500 / \mu l$ & $6(30)$ & $12(26.5) \ddagger$ & $18(32.1) \S$ & $135(54.9)$ \\
\hline $\begin{array}{l}\text { Median time (year) from } \\
1^{\text {st }} \text { HIV-positive test (range) }\end{array}$ & $11.5(0.1-27)+\dagger$ & $12(0.1-25) \mathrm{c}$ & $12(0.1-27)+\dagger$ & $9.5(0.1-23)$ \\
\hline Contact with patients with TB & $13(65) \S$ & $4(8.9)$ & $24(42.9)+\dagger$ & $69(28.2)$ \\
\hline History of injection drug use & $15(75) \dagger$ & $24(53.3)$ & $33(58.8)+\dagger$ & $105(42.7)$ \\
\hline History of prior prison stay & $12(60) \dagger$ & $24(53.3)$ & $21(37.1) \S$ & $39(17.9)$ \\
\hline Lived in a shelter or homeless & $11(55) \dagger$ & $10(25.2)$ & $18(32.1)$ & $48(19.5)$ \\
\hline Hepatitis C virus co-infection & $14(70)$ c & $20(44.5)$ & $28(50.0)$ & $92(37.7)$ \\
\hline
\end{tabular}

NOTE. Data are no (\%) of patients unless otherwise indicated.

ART, antiretroviral therapy; BCG, Bacille Calmette-Guérin; QFG, QuantiFERON-TB Gold, Mc: Manufacturer's interpretation criteria.

The numbers printed in bold letters indicate the value of variables significantly associated with positive test results in univariate analyses: $\dagger+p=0.04 ; \dagger p=0.02 \S$ $\mathrm{p}=0.002 ; \mathrm{p}=0.009 ; \mathrm{p}<0.001 ;{ }^{*}$ comparing TST positive $(\mathrm{n}=20)$ with TST negative patients $(\mathrm{n}=282) ;{ }^{* *}$ comparing QFG or T.SPOT.TB positive $(\mathrm{n}=45)$ with QFG or T.SPOT-TB (Mc) negative patients $(n=257) ;{ }^{* * *}$ comparing either TST, QFG or T-SPOT.TB (Mc) positive $(n=56)$ with all tests (TST, QFG and T.SPOT.TB-Mc) negative $(n=246)$. 


\section{Discussion}

To our knowledge this is the largest study to date to evaluate QFG and T-SPOT.TB tests and to define its usefulness, compared with that of TST, in the diagnosis of LTBI in HIV-infected patients in a middle-low TB incidence setting. We found that IGRAs were more sensitive than TST for the diagnosis of $M$. tuberculosis infection. T-SPOT.TB test gave the largest number of positive results using either manufacturer's criteria or FDA's criteria. Noteworthy, T-SPOT.TB was positive in many patients with a negative TST result, thus indicating that dual sequential testing with TST and IGRAs may be the optimal approach for LTBI screening in HIV-infected patients. Previous studies had shown that IGRAs have higher specificity than TST in low TB incidence settings $[7,9,10,12,13,20]$, but did not specifically assess the contribution of IGRAs to the diagnosis of LTBI in patients with HIV infection. Therefore, this study expands upon the evaluation of IGRA and offers relevant information on its potential clinical usefulness.

As found in previous studies performed in HIVinfected patients $[10,12,13,21]$, agreement between the IGRA tests and TST was moderate or poor, and indeterminate test results occurred in a significant proportion of the patients. As expected [12,13], a higher rate of indeterminate results was found with the T-SPOT.TB test than with QFG. In agreement with previous studies $[12,13,20]$ indeterminate results of QFG were associated with CD4 count of $<200 \mathrm{cell} / \mu \mathrm{l}$, while the same did not occur for T-SPOT.TB test. By contrast, indeterminate results for T-SPOT.TB have been related to older age and conditions of transportation [22].

In our study, T-SPOT.TB outperformed QFG. The proportion of individuals testing positive has also been found significantly greater with T-SPOT.TB than with QFG in other studies conducted in asymptomatic HIVinfected patients [11-13,20]. The higher performance of T-SPOT.TB with respect to QFG is in line with previous data indicating that T-SPOT.TB may be less affected by advanced immunosuppression [21,23], and supported by investigations conducted in persons with cultureconfirmed active TB $[24,25]$. In a recent meta-analysis, pooled sensitivity estimates in culture-confirmed active TB were higher for T-SPOT.TB than for QFG [21]. In studies carried out in countries with low prevalence of $\mathrm{TB}$, sensitivity was $94 \%$ for T-SPOT.TB [24]. In the study of Sauzullo et al the sensitivity of QFG was 67\%, not higher than that of TST in head-to-head comparison [25]. It should be stated, however, that we did not use the most reliable method for counting SFU, the automated ELISPOT plate reader, and therefore misclassification of some of our results can not be ruled out.

Studies evaluating new laboratory techniques used for the diagnosis of LTBI face a major challenge, which is the lack of a satisfactory "gold standard" for assessing both sensitivity and specificity, particularly in HIV-infected patients. The patients with past, current history of TB or LTBI had a higher frequency of positive tests presumably because of a persistent immune response. Those patients were included in the study as "positive controls", to assess the yield and reliability of the tests in the subset of patients who retained persistent immune response.

Whereas prospective cohort studies have shown that persons with a positive TST result have an increased risk of developing active TB compared with persons with negative TST result $[1,26]$, there is a general agreement that TST has low sensitivity, and it is assumed that TST positive cases represent only a portion of the cases of LTBI. Based on the test-positive rate among patients with culture-confirmed TB, IGRAs are considered to be more sensitive than TST [27]. Indeed, in our cohort, T-SPOT.TB was more frequently positive than TST, particularly in patients with no past or current TB nor treatment for LTBI.

A number of studies have pointed out that IGRAs may also have a higher specificity than TST for the diagnosis of LTBI in low TB incidence settings and correlate better with surrogate markers of $M$. tuberculosis exposure $[27,28]$. Although data from large prospective cohort studies evaluating the clinical impact and predictive value of IGRA testing are currently lacking, available information suggests that these tests may predict the subsequent development of active TB in certain patient populations even better than TST $[29,30]$. In a recent study in male patients with silicosis without clinical suspicion of active $\mathrm{TB}$, past history of $\mathrm{TB}$, and treatment for LTBI, T-SPOT.TB outperformed TST in predicting TB disease [29], and a recent meta-analysis that included studies of HIV-infected and HIV-uninfected patients found that IGRAs results are more strongly associated with progression to active TB than TST results [30].

Interestingly, in our study, T-SPOT.TB increased the detection of $M$. tuberculosis infection in patients with negative TST by $7.3 \%$ when using the FDA's interpretation criteria or by $11.9 \%$ according to the manufacturer's interpretation criteria. There is little information on the significance of a positive IGRAs result with negative TST in HIV-infected individuals. Four previous longitudinal studies have evaluated the ability of IGRAs to predict future development of active TB in HIV-infected individuals and all of them reported a higher risk of active TB in individuals with positive IGRAs results [24,31-33]. However, in all of the 3 studies the duration of follow-up was limited and had few incident cases of active TB [21]. Unfortunately, our study design did not allow evaluating the clinical impact of implementing IGRAs in LTBI screening, neither the predictive value for active $\mathrm{TB}$ of a positive IGRAs result in patients with TST negative. The rate of 
anergic patients was also unknown because no additional skin tests to the TST were performed.

\section{Conclusions}

Our study suggests that IGRAs, particularly T-SPOT.TB, may have a role for identifying $M$. tuberculosis infection in HIV-infected individuals, and support a dual testing approach, starting with TST and performing T-SPOT.TB if the TST is negative. Although we were unable to identify a typical patient profile with TST negative but IGRAs positive, T-SPOT.TB is more likely to be useful in patients with no past or current TB nor treatment for LTBI, a setting in which sensitivity of T-SPOT.TB was twice that of TST. Whether T-SPOT.TB truly identifies HIV-infected individuals who would benefit from preventive therapy remains unanswered. Further studies are required to establish the clinical impact and cost-effectiveness of dual testing approaches in clinical practice.

\section{Competing interests}

The authors declare that they have no competing interests.

\section{Authors' contributions}

Conceived and designed the experiments: JMR FG. Data collection: JMR, MM, SP. Performed the experiments: CR SB, JCR. Analyzed the data: JMR MM FG. Contributed reagents/materials/analysis tools: CR, SB, JCR. Wrote the paper: JMR MM FG. All authors discussed the results and commented on the manuscript and all read and approved the final manuscript.

\section{Acknowledgements}

This work was supported in part by grants from Conselleria de Sanidad (051/ 2007), FIS (PI08/90778), FIBELX (10/12), Generalitat Valenciana (AP-087/10) and ISCIII-RETIC RD06/0027-FEDER-Red Temática Cooperativa de Investigación en SIDA.

Presented in part 50th Interscience Conference on Antimicrobial Agents and Chemotherapy (ICAAC). Boston, USA, September 2010 [Abstract H-231].

\section{Author details}

${ }^{1}$ Infectious Diseases Unit, Hospital General Universitario de Elche, Camino de la Almazara, 12, 03203, Elche, Alicante, Spain. ${ }^{2}$ Section of Microbiology, Hospital General Universitario de Elche, Camino de la Almazara, 12, 03203, Elche, Alicante, Spain. ${ }^{3}$ Department of Clinical Medicine, University Miguel Hernández, Ctra, Valencia s/n, 03550, San Juan de Alicante, Alicante, Spain.

Received: 26 October 2011 Accepted: 16 July 2012

Published: 31 July 2012

\section{References}

1. Elzi L, Schlegel M, Weber R, Hirschel B, Cavassini M, Schmid P, Bernasconi E, Rickenbach M, Furrer H, Swiss HIV Cohort Study: Reducing tuberculosis incidence by tuberculin skin testing, preventive treatment, and antiretroviral therapy in an area of low tuberculosis transmission. Clin Infect Dis 2007, 44:94-102.

2. American Thoracic Society; Centers for Disease Control and Prevention; Infectious Diseases Society of America: American Thoracic Society/Centers for Disease Control and Prevention/Infectious Diseases Society of America: controlling tuberculosis in the United States. Am J Respir Crit Care Med 2005, 172:1169-1127.

3. Blumberg HM, Leonard MK Jr, Jasmer RM: Update on the treatment of tuberculosis and latent tuberculosis infection. JAMA 2005, 293:2776-2784.

4. Selwyn PA, Sckell BM, Alcabes P, Friedland GH, Klein RS, Schoenbaum EE: High risk of active tuberculosis in HIV-infected drug users with cutaneous anergy. JAMA 1992, 268:504-509.

5. Lalvani A, Pareek M: Interferon gamma release assays: principles and practice. Enferm/nfeccMicrobio/Clin 2010, 28:245-252.
6. Mazurek M, Jereb J, Vernon A, LoBue P, Goldberg S, Castro K, IGRA Expert Committee; Centers for Disease Control and Prevention (CDC): Updated guidelines for using Interferon Gamma Release Assays to detect Mycobacterium tuberculosis infection - United States, 2010. MMWR Recomm Rep 2010, 59(RR-5):1-25.

7. Brock I, Ruhwald M, Lundgren B, Westh $H$, Mathiesen LR, Ravn P: Latent tuberculosis in HIV positive, diagnosed by the M. tuberculosis specific interferon-gamma test. Respir Res 2006, 7:56.

8. Balcells ME, Pérez CM, Chanqueo L, Lasso M, Villanueva M, Espinoza M, Villarroel L, García P: A comparative study of two different methods for the detection of latent tuberculosis in HIV-positive individuals in Chile. Int J Infect Dis 2008, 12:645-652.

9. Jones S, de Gijsel D, Wallach FR, Gurtman AC, Shi Q, Sacks H: Utility of QuantiFERON-TB Gold in-tube testing for latent TB infection in HIVinfected individuals. Int J Tuberc Lung Dis 2007, 11:1190-1195.

10. Luetkemeyer AF, Charlebois ED, Flores LL, Bangsberg DR, Deeks SG, Martin $J N$, Havlir DV: Comparison of an interferon-gamma release assay with tuberculin skin testing in HIV-infected individuals. Am J Respir Crit Care Med 2007, 175:737-742.

11. Rangaka MX, Wilkinson KA, Seldon R, Van Cutsem G, Meintjes GA, Morroni C, Mouton P, Diwakar L, Connell TG, Maartens G, Wilkinson RJ: Effect of HIV-1 infection on T-Cell-based and skin test detection of tuberculosis infection. Am J Respir Crit Care Med 2007, 175:514-520.

12. Stephan C, Wolf T, Goetsch U, Bellinger O, Nisius G, Oremek G, Rakus Z, Gottschalk R, Stark S, Brodt HR, Staszewski S: Comparing QuantiFERONtuberculosis gold, T-SPOT tuberculosis and tuberculin skin test in HIV-infected individuals from a low prevalence tuberculosis country. AIDS 2008, 22:2471-2479.

13. Talati NJ, Seybold U, Humphrey B, Aina A, Tapia J, Weinfurter P, Albalak R, Blumberg HM: Poor concordance between interferon-gamma release assays and tuberculin skin tests in diagnosis of latent tuberculosis infection among HIV-infected individuals. BMC Infect Dis 2009, 9:15.

14. American Thoracic Society, Centers for Disease Control and Prevention: Diagnostic standards and classification of tuberculosis in adults and children. Am J Respir Crit Car Med 2000, 161:1376-1395.

15. Cellestis Limited. QuantiFERON-TB Gold. Available at: http://www.cellestis.com. Accessed 20 February 2011

16. Oxford Immunotec Limited. T-SPOT.TB. Available at: http://www. oxfordimmunotec.com/T-SPOT_International. Accessed 20 February 2011.

17. User instructions. Microcapture Software. Available at: http://videopen.narod. ru/usb-ustroistva/usb-mikroskop-200x-8-led/microcapture.pdf. Accessed 1 May 2012

18. Food and Drug Administation: T-SPOT-TB - PO70006. Available at: http://fda gov/MedicalDEvices/ProductsandMedicalProcedures/ DEciveApprovalsandClearances/PMAAAprovals/ucm102794.htm. Accessed 20 February 2011.

19. Landis JR, Koch GC: The measurement of observer agreement for categorical data. Biometrics 1977, 33:159-174.

20. Mandalakas AM, Hesseling AC, Chegou NN, Kirchner HL, Zhu X, Marais BJ, Black GF, Beyers N, Walzl G: High level of discordant IGRA results in HIV-infected adults and children. Int J Tuberc Lung Dis 2008, 12:417-423.

21. Beffa $P$, Zellweger $A$, Janssens JP, Wrighton-Smith P, Zellweger JP: Indeterminate test results of T-SPOT.TB performed under routine field conditions. Eur Respir J 2008, 31:842-6.

22. Cattamanchi A, Smith R, Steingart KR, Metcalfe JZ, Date A, Coleman C, Marston BJ, Huang L, Hopewell PC, Pai M: Interferon-Gamma Release Assays for the Diagnosis of Latent Tuberculosis Infection in HIV-Infected Individuals: A Systematic Review and Meta-Analysis. J Acquir Immune Defic Syndr 2011, 56:230-238.

23. Dheda K, Lalvani A, Miller RF, Scott G, Booth H, Johnson MA, Zumla A, Rook GA: Performance of a T-cell-based diagnostic test for tuberculosis infection in HIV-infected individuals is independent of CD4 cell count. AIDS 2005, 19:2038-2041.

24. Clark SA, Martin SL, Pozniak A, Steel A, Ward B, Dunning J, Henderson DC, Nelson M, Gazzard B, Kelleher P: Tuberculosis antigen-specific immune responses can be detected using enzyme-linked immunospot technology in human immunodeficiency virus (HIV)-1 patients with advanced disease. Clin Exp Immunol 2007, 150:238-244.

25. Sauzullo I, Mengoni F, Scrivo R, Valesini G, Potenza C, Skroza N, Marocco R, Lichtner M, Vullo V, Mastroianni CM: Evaluation of QuantiFERON-TB Gold In-Tube in human immunodeficiency virus infection and in patient 
candidates for anti-tumour necrosis factor-alpha treatment. Int I Tuberc Lung Dis 2010, 14:834-840.

26. Markowitz N, Hansen NI, Hopewell PC, Glassroth J, Kvale PA, Mangura BT, Wilcosky TC, Wallace JM, Rosen MJ, Reichman LB, The Pulmonary Complications of HIV Infection Study Group: Incidence of tuberculosis in the United States among HIV-infected persons. Ann Intern Med 1997, 126:123-132.

27. Pai M, Zwerling A, Menzies D: Systematic review: T-cell-based assays for the diagnosis of latent tuberculosis infection: an update. Ann Intern Med 2008, 149:177-184.

28. Menzies D, Pai M, Comstock G: Meta-analysis: new tests for the diagnosis of latent tuberculosis infection: areas of uncertainty and recommendations for research. Ann Intern Med 2007, 146:340-354.

29. Leung CC, Yam WC, Yew WW, Ho PL, Tam CM, Law WS, Au KF, Tsui P: T-Spot.TB outperforms tuberculin skin test in predicting tuberculosis disease. Am J Respir Crit Care Med 2010, 182:834-840.

30. Diel R, Goletti D, Ferrara G, Bothamley G, Cirillo D, Kampmann B, Lange C, Losi M, Markova R, Migliori GB, Nienhaus A, Ruhwald M, Wagner D, Zellweger JP, Huitric E, Sandgren A, Manissero D: Interferon- $\gamma$ release assays for the diagnosis of latent Mycobacterium tuberculosis infection: a systematic review and meta-analysis. Eur Respir J 2011, 37:88-99.

31. Aichelburg MC, Rieger A, Breitenecker F, Pfistershammer K, Tittes J, Eltz S, Aichelburg AC, Stingl G, Makristathis A, Kohrgruber N: Detection and prediction of active tuberculosis disease by a whole-blood interferongamma release assay in HIV-1-infected individuals. Clin Infect Dis 2009, 48:954-962.

32. Elliott JH, Vohith K, Saramony S, Savuth C, Dara C, Sarim C, Huffam S, Oelrichs R, Sophea P, Saphonn V, Kaldor J, Cooper DA, Chhi Vun M, French MA: Immunopathogenesis and diagnosis of tuberculosis and tuberculosis-associated immune reconstitution inflammatory syndrome during early antiretroviral therapy. J Infect Dis 2009, 200:1736-1745.

33. Jonnalagadda S, Lohman Payne B, Brown E, Wamalwa D, Maleche Obimbo E, Majiwa M, Farquhar C, Otieno P, Mbori-Ngacha D, John-Stewart G: Latent tuberculosis detection by interferon $\gamma$ release assay during pregnancy predicts active tuberculosis and mortality in human immunodeficiency virus type 1-infected women and their children. J Infect Dis 2010, 202:1826-1825.

doi:10.1186/1471-2334-12-169

Cite this article as: Ramos et al:: Contribution of Interferon gamma release assays testing to the diagnosis of latent tuberculosis infection in HIV-infected patients: A comparison of QuantiFERON-TB Gold In Tube, T-SPOT.TB and tuberculin skin test. BMC Infectious Diseases 2012 12:169.

\section{Submit your next manuscript to BioMed Central and take full advantage of:}

- Convenient online submission

- Thorough peer review

- No space constraints or color figure charges

- Immediate publication on acceptance

- Inclusion in PubMed, CAS, Scopus and Google Scholar

- Research which is freely available for redistribution 